\title{
Experimental Study on Tunnel Fire Behaviors under Natural Ventilation Using Shafts
}

\author{
Chuangang Fan, Jie Ji, and Jinhua Sun
}

\begin{abstract}
Tunnel safety has drawn public attention due to the occurrence of many catastrophic fires in recent years. Meanwhile, natural ventilation types such as solar chimney and vertical shaft have become popular in relevant constructions. However, natural ventilation mode using shafts in tunnel fires are still lacking in quantitative analyses. In this study, a set of model scale experiments was carried out to investigate the influence of natural ventilation using shafts on tunnel fire behaviors. Two kinds of fuel, methanol and n-heptane, were used to model the fire in a small scale tunnel and three shafts were employed. The effects of natural ventilation on fire burning rate, fire plume temperature and flame height were investigated detailedly and the experimental results were compared with the previous studies.
\end{abstract}

Index Terms—Flame, natural ventilation, shaft, tunnel fire.

\section{INTRODUCTION}

Owing to numerous catastrophic tunnel fires, such as the Mont Blanc tunnel fire in 1999 and the Daegu subway fire in 2003, the interest in tunnel fire safety has increased dramatically in recent years. According to statistics, $85 \%$ of the deaths in building fires were caused by toxic smoke [1]. In order to effectively discharge fire-induced smoke, ventilation for tunnels can be provided by natural or mechanical systems.

Compared with mechanical ventilation with costly maintenance and electrical energy consumption, natural ventilation using vertical shafts can avoid air fans that will reduce the tunnel section height and does not consume power in the operation process [2]. Nowadays, more and more tunnels are adopting natural ventilation mode.

Tong et al. [3] conducted full-scale burning tests in a road tunnel with natural ventilation using shafts and found that large amounts of smoke and heat were released through shafts. Wang et al. [4] conducted a set of burning experiments in a full-scale tunnel with roof openings, tested the effect of natural smoke exhaust and investigated the ceiling jet temperature and backflow distance. Kashef et al. [5] conducted a series of tests in two 1/15 reduced-scale tunnels to investigate the ceiling temperature distribution and smoke diffusion in tunnel fires with natural ventilation. Based on experimental results and one-dimensional theory, formulas to predict the temperature distribution and smoke

Manuscript received May 8, 2014; revised July 20, 2014. This work was supported by National Natural Science Foundation of China (NSFC) under Grant No. 51376173 and Program for New Century Excellent Talents in University under Grant No. NCET-13-0540.

The authors are with State Key Laboratory of Fire Science, University of Science and Technology of China, Hefei, China (e-mail: jijie232@ustc.edu.cn). diffusion extent were developed.

In the former studies of our group, the dynamic characteristics of smoke movement under the action of natural ventilation with vertical shafts were studied systemically by theoretical analysis and experimental research. The generation mechanism of plug-holing (i.e. the fresh air is drawn directly into the smoke exhausting shaft from the lower layer) under the stack effect induced inside the shaft was revealed and the critical criterion was established [6]. The influence of longitudinal wind on natural ventilation with vertical shafts was demonstrated [7]. The boundary layer separation occurring near the right-angle connection of the shaft and the tunnel ceiling was discovered and a method with pertinence was brought forward [8].

However, all the former studies are focused on the smoke exhausting process when the fire source is kept with a relatively long distance from the shaft. In the study on fire-induced smoke movement in stairwell of a high rise building and influence of stack effect on the adjacent compartment combustion [9], it was found that the fire burning rate was accelerated by the stack effect in the stairwell as air convection was enhanced by the stack effect. The air flow induced by stack effect also made the flame nearly incline to horizontal. For the tunnel fire case, when the fire source is distant from the shaft, the fire-induced smoke flowing into the shaft generates the stack effect. And when the fire is located under the shaft, the stronger stack effect will occur as the hot smoke inside the shaft has a higher temperature. Thus, it is necessary to investigate the combustion behaviors, especially whether the relatively strong stack effect can accelerate the burning rate largely and then influence the fire spread to other vehicles from the ignited one. In this study, a set of model scale experiments was carried out to investigate the tunnel fire behaviors under natural ventilation when the fire is located under the shaft.

\section{EXPERIMENTS}

The experiments were conducted in a model tunnel as shown in Fig. 1. A scale ratio of 1: 6 is applied in current cases. The tunnel is $6 \mathrm{~m}$ long, $2 \mathrm{~m}$ wide and $0.88 \mathrm{~m}$ high. The Froude modeling is applied to build up the physical scale model. By holding the Froude number constant, the corresponding relationships can be simplified to obtain the required scaling laws.

Pool fires were burned with two representative kinds of fuels, methanol and n-heptane. Square methanol pools (10, 15 and $20 \mathrm{~cm}$ length) and n-heptane pools $(5,7.5$ and $10 \mathrm{~cm}$ length), ignited by a torch, and were used as burning objects, which provided a set of fixed burning areas. All the pools 
were made by $2 \mathrm{~mm}$ thick steel board with depth of $4.5 \mathrm{~cm}$. In all tests, the distance from the pool to the tunnel ceiling was $0.66 \mathrm{~m}$. The longitudinal distance between the pool (or the $0.8 \mathrm{~m}$ high shaft) and the right tunnel opening is about $2 \mathrm{~m}$.

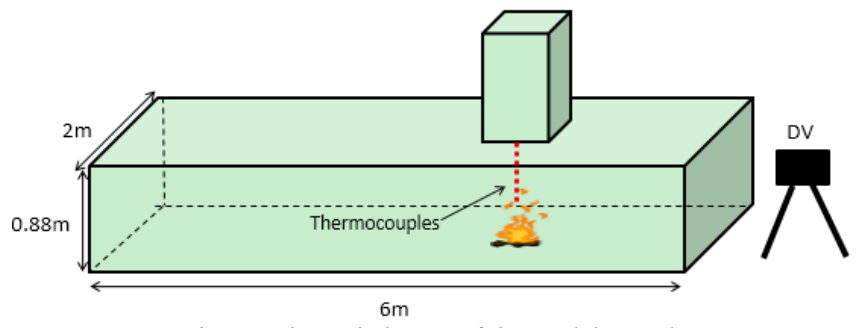

Fig. 1. Schematic layout of the model tunnel.

The burning rate was recorded using a scale with maximum capacity of $30 \mathrm{~kg}$ and uncertainty of $0.1 \mathrm{~g}$. During the burning tests, the scale was positioned underneath the pool and protected by fire-resistant sheets. The amount of fuel was chosen to allow for approximate 10 min duration of burning in each experiment.

One set of thermocouples with $5 \mathrm{~cm}$ interval was mounted vertically above the pool. All thermocouples were type $\mathrm{K}$ with an uncertainty of less than $3 \mathrm{~K}$. All measurements were recorded every $1 \mathrm{~s}$. In order to observe the flame development of the pool fires, a Digital Vidicon was used to record the flame image.

The test series comprised 24 experiments with varying fuel type, pool size and shaft size $(20 \mathrm{~cm} \times 20 \mathrm{~cm}, 30 \mathrm{~cm} \times 30 \mathrm{~cm}$, $50 \mathrm{~cm} \times 50 \mathrm{~cm})$. Moreover, the benchmark tests without shaft installed on the tunnel ceiling were also conducted. Each case was repeated once. ubmit your manuscript electronically for review.

\section{RESUlts AND DisCUSSION}

In this study, the influence of stack effect induced by the ventilation shaft on the fire behaviors will be researched from these aspects: fire burning rate, flame temperature and height.

Fig. 2 shows the fire burning rate in steady state for different pools. For both fuels, the burning rate keeps nearly unchanged with the increase of shaft size, which proves that the burning behavior of pool fire is not affected distinctly by the stack effect, and the burning rate in natural ventilation cases is similar with that in case without shaft installed on the tunnel ceiling. As the fire pools are not very big and the corresponding fire flames are a little small without forming a strong ceiling flame, the combustion of the pool fire should not be ventilation controlled. Although the shaft exhausts a number of smoke by the stack effect, it will not bring an evident influence on the air entrainment of the fire plume and thus the combustion behavior.

The fire plume can be characterized by three distinct zones: continuous flame zone, intermittent flame zone and buoyant plume zone. McCaffery [10] established the boundaries and temperature characteristics of the three zones, based on methane fire tests:

$$
\frac{2 g \Delta T}{T_{0}}=\left(\frac{k}{0.9}\right)^{2}\left(\frac{z}{Q^{2 / 5}}\right)^{2 \eta-1}
$$

where $\Delta T$ is plume temperature rise above ambient, $g$ is gravity acceleration, $T_{\underline{Q}}$ is ambient temperature, $z$ is vertical height above burner, $Q$ is fire power, and $k$ and $\eta$ are empirical parameters that vary depending on the plume region as shown in Table I. It should be noted that in this work, the fire power is calculated by multiplying the burning rate in steady state, heat of combustion and combustion efficiency.

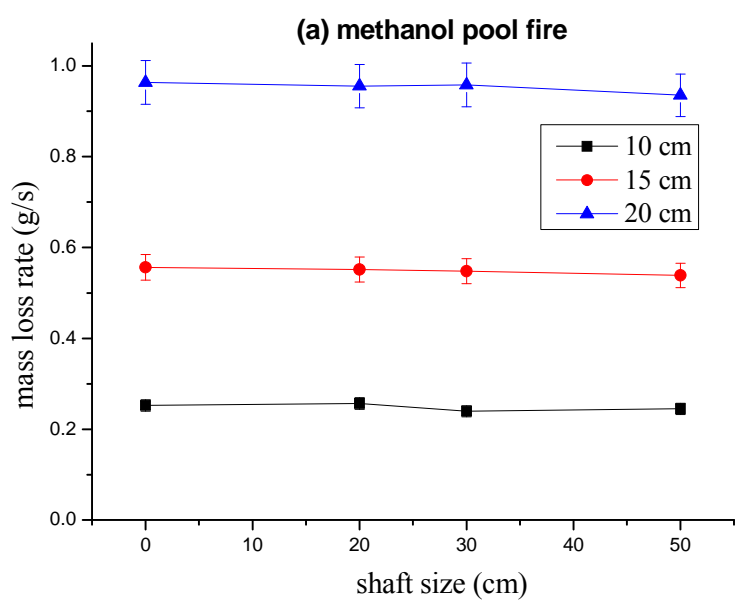

(b) n-heptane pool fire

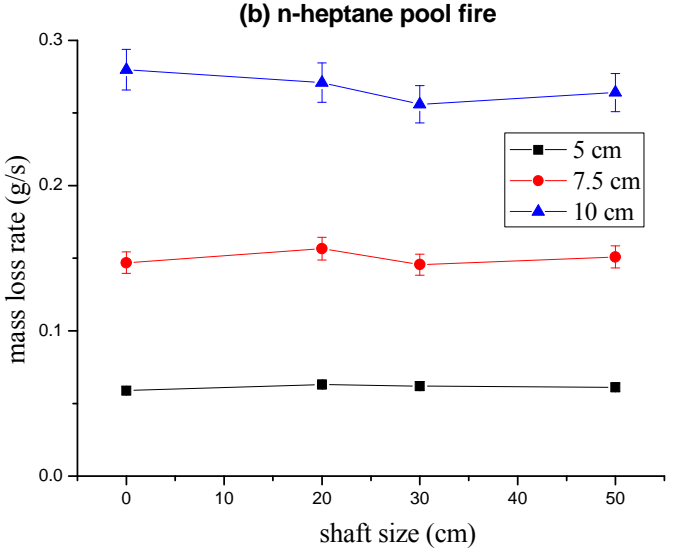

Fig. 2. Burning rate in steady state for different pools (shaft size- $0 \mathrm{~cm}$ represents the case without shaft installed on the tunnel ceiling).

TABLE I: EMPIRICAL PARAMETERS IN MCCAFFREY EQUATION

\begin{tabular}{|c|c|c|c|}
\hline \multirow{2}{*}{ Plume Zone } & \multicolumn{3}{|c|}{ Empirical parameters } \\
\cline { 2 - 4 } & $k$ & $\eta$ & $z / Q^{2 / 5}$ \\
\hline Continuous flame & 6.9 & $1 / 2$ & $<0.08$ \\
\hline Intermittent flame & 1.9 & 0 & $0.08-0.2$ \\
\hline Buoyant plume & 1.1 & $-1 / 3$ & $>0.2$ \\
\hline
\end{tabular}

The relationship between fire plume temperature rise and $z / Q^{2 / 5}$ is shown in Fig. 3, combined with the McCaffrey equation. Based on Fig. 3a, the plume temperature rise in the case without shaft installed on the tunnel ceiling correlates well with the predicted result by the McCaffrey theory. For cases with natural ventilation, in the continuous flame zone, the plume temperature rises are nearly the same with those without natural ventilation. However, in the intermittent flame zone and buoyant plume zone, the plume temperature rises are evidently lower than those without natural ventilation, which is mainly caused by the fact that some smoke are exhausted rapidly from the shaft by the stack effect, 
along with some of heat induced by the combustion process. This is beneficial for the fire protection of the concrete.
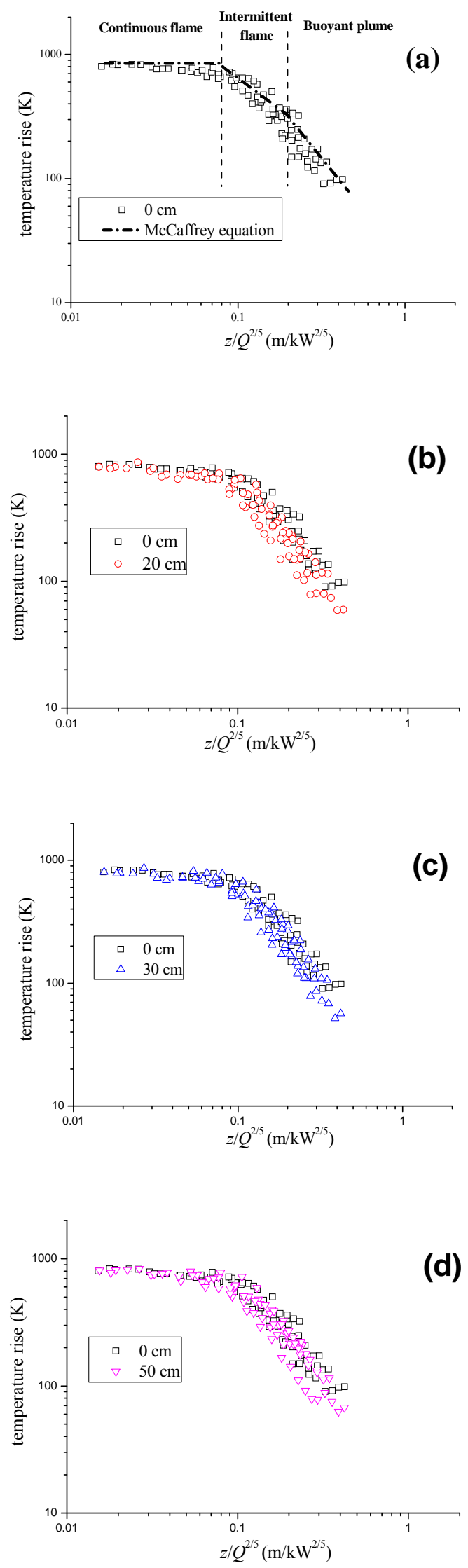

Fig. 3. Fire plume temperature rise with $z / Q^{2 / 5}$ in cases with different shaft sizes.

The mean flame height is an important parameter that marks the level where the combustion reactions are essentially complete. According to the study of Heskestad [11], the flame height can be expressed as Eq. (2) for square or circular pool fires:

$$
\frac{L}{D}=-1.02+3.7 Q^{* 2 / 5}, Q^{*}=Q /\left(\rho_{0} c_{p} T_{0} g^{1 / 2} D^{5 / 2}\right)
$$

where $L, D, \rho_{0}$ and $c_{p}$ are flame height, equivalent diameter of fire source, ambient air density and specific heat capacity, respectively. In this research, a new method for flame image segmentation is used [12]. This method uses the cube root of four color channels to form a pseudo-gray image, which has better segmentation result than directly applying Otsu's method to grayscale image. The dimensionless flame height with dimensionless fire power in steady state is shown in Fig. 4. On the whole, the Heskestad equation predicts well for all the results, whether the natural ventilation using shafts is employed or not, which demonstrates that the stack effect induced by the hot smoke flowing into the shaft will not lead to a significant stretching of the flame, as speculated before conducting the tests.

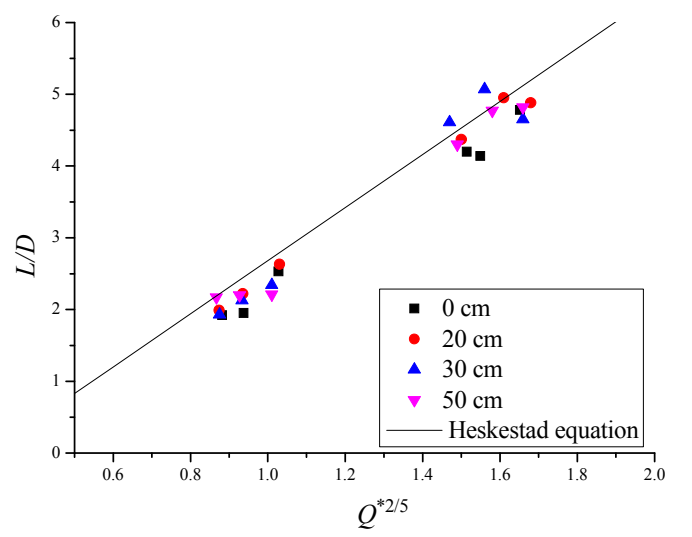

Fig. 4. Dimensionless flame height with dimensionless fire power.

\section{CONClusion}

In former studies, fires were always assumed to occur with a relatively long distance from the shaft. In fact, fires will occur at any location in tunnels, including the location under the shaft. Therefore, a total of 24 experiments with varying fuel type, pool size and shaft size were carried out to study the influence of natural ventilation using shafts on tunnel fire behaviors. The major results are summarized as follows:

1) For both fuels, the burning rate keeps nearly unchanged with the increase of shaft size, which proves that the burning behavior of pool fire is not affected distinctly by the stack effect, and the burning rate in natural ventilation cases is similar with that in case without shaft installed on the tunnel ceiling. Although the shaft exhausts a number of smoke by the stack effect, it will not bring an evident influence on the air entrainment of the fire plume and thus the combustion behavior.

2) For cases with natural ventilation, in the continuous flame zone, the plume temperature rises are nearly the same with those without natural ventilation, however, in 
the intermittent flame zone and buoyant plume zone, the plume temperature rises are evidently lower than those without natural ventilation, which is mainly caused by the rapid exhaust of heat by the stack effect.

3) The Heskestad equation predicts well for the flame height in our cases, whether the natural ventilation using shafts is employed or not, proving that the stack effect induced by the hot smoke flowing into the shaft will not lead to a significant stretching of the flame.

\section{REFERENCES}

[1] Y. Alarie, "Toxicity of fire smoke," $C R C$ Critical Reviews in Toxicology, vol. 32, no. 4, pp. 259-289, 2001.

[2] C. G. Fan, J. Ji, Z. H. Gao, J. Y. Han, and J. H. Sun, "Experimental study of air entrainment mode with natural ventilation using shafts in road tunnel fires," Int J Heat Mass Tran, vol. 56, no. 1-2, pp. 750-757, 2013.

[3] Y. Tong, M. H. Shi, Y. F. Gong, and J. P. He, "Full-scale experimental study on smoke flow in natural ventilation road tunnel fires with shafts," Tunn Undergr Sp Tech, vol. 24, no. 6, pp. 627-633, 2009.

[4] Y. Wang, J. Jiang, and D. Zhu, "Full-scale experiment research and theoretical study for fires in tunnels with roof openings," Fire Safety $J$, vol. 44, no. 3, pp. 339-348, 2009.

[5] A. Kashef, Z. Yuan, and B. Lei, "Ceiling temperature distribution and smoke diffusion in tunnel fires with natural ventilation," Fire Safety $J$, vol. 62, no. Part C, pp. 249-255, 2013.

[6] J. Ji, Z. H. Gao, C. G. Fan, W. Zhong, and J. H. Sun, "A study of the effect of plug-holing and boundary layer separation on natural ventilation with vertical shaft in urban road tunnel fires," Int $J$ Heat Mass Tran, vol. 55, no. 21-22, pp. 6032-6041, 2012.

[7] W. Zhong, C. G. Fan, J. Ji, and J. P. Yang, "Influence of longitudinal wind on natural ventilation with vertical shaft in a road tunnel fire," Int J Heat Mass Tran, vol. 57, no. 2, pp. 671-678, 2013.
[8] J. Ji, C. G. Fan, Z. H. Gao, and J. H. Sun, "Effects of vertical shaft geometry on natural ventilation in urban road tunnel fires," Journal of Civil Engineering and Management, 2014, to be published.

[9] X. Q. Sun, "Studies on smoke movement and control in shafts and stairwell in High-rise Buildings," Ph.D. dissertation, University of Science and Technology of China, Hefei, China, 2009.

[10] B. J. McCaffrey, "Purely buoyant diffusion flames: some experimental results," National Institute of Standards and Technology, 1979.

[11] G. Heskestad, "Luminous heights of turbulent diffusion flames," Fire Safety J, vol. 5, no. 2, pp. 103-108, 1983.

[12] W.G. Yan, C. J. Wang, and J. Guo, "One Extended OTSU Flame Image Recognition Method Using RGBL and Stripe Segmentation," Applied Mechanics and Materials, vol. 121, pp. 2141-2145, 2012.

Chuangang Fan is a doctoral student specializing in fire safety engineering at State Key Laboratory of Fire Science, University of Science and Technology of China from September 2010 to present. His research interest includes smoke spread and control for underground buildings and computational fluid dynamics.

Jie Ji completed his $\mathrm{PhD}$ degree in fire safety engineering from State Key Laboratory of Fire Science, University of Science and Technology of China in 2008. He is an associate professor at the Lab now, and his research interest includes smoke movement and ventilation control method in building fires and characteristics of flame spread over surface of solid combustibles.

Jinhua Sun is a professor at State Key Laboratory of Fire Science, University of Science and Technology of China, and he is the director of the international association for fire safety science from 2008 to present. His main research interests are fire dynamics and basic fire prevention technologies, large-scale evacuation and rescue in emergencies, hazardous chemical disaster prediction and prevention methods. To date he has authored over 200 research papers of which 100 were indexed by SCI and EI, and six books. 